\title{
La catalogación de materias: apuntes históricos sobre su normalización
}

\author{
A catalogação de assunto: apontamentos históricos e a sistematização de regras
}

Subject cataloguing: historical notes on its standarization

Noemi Oliveira MARTINHO (1), Mariângela Spotti Lopes FUJITA (2)

Universidade Estadual Paulista Júlio de Mesquita Filho - UNESP, Departamento de Ciência da Informação, Av. Hygino Muzzi Filho, 737, Campus Universitário, CEP. 17525-900 - Marília-SP - Brasil, Caixa-Postal 421, (1) oemiy@marilia.unesp.br (2) fujita@marilia.unesp.br

\begin{abstract}
Resumen
La catalogación de materias, a pesar de su significativa trayectoria histórica en el campo de la organización de la información, no ha sido tan discutida como la catalogación descriptiva, a pesar de ser oriundas del mismo proceso. Al rescatar la historia de la catalogación, se percibe que se produjo una dicotomía entre los procesos descriptivo y de materia, y que el primero recibió más énfasis en el desarrollo de los códigos de catalogación y formatos de intercambio. No obstante, los estudios de catalogación de materia se constituyen como un punto fundamental para sustentar los productos de apoyo a la investigación documental, como los catálogos bibliográficos.

Palabras clave: Catalogación temática. Charles Ammi Cutter. Reglas de catalogación temática. Encabezamientos de materia.
\end{abstract}

\section{Introdução}

O desenvolvimento da Biblioteconomia e da Ciência da Informação pautou-se pela necessidade de organização, e mais do que isso, da representação da informação de forma a garantir a sua localização e acesso.

O trânsito e acesso à informação é um dos principais desafios e necessidade das bibliotecas. Dessa forma, diversos países passaram a envidar esforços em busca do propósito de otimizar seus serviços de representação garantindo o acesso a informação.

Inicialmente ocorrida de forma pragmática, a sistematização da organização da informação pautou-se por problemas particulares de cada instituição, o que mais tarde se verificou ser em essência comum a todas. De problemas práticos e particulares constatou-se a necessidade de conceitos teóricos, princípios epistemológicos norteadores do desenvolvimento da área não apenas enquanto fazer prático e utilitário, mas enquanto campo científico legítimo e formalmente constituído.

\begin{abstract}
Subject cataloguing, in spite of its expressive historical trajectory in the information organization field, has not received as much attention as descriptive cataloguing, although they are part of the same process. Reviewing the history of cataloguing, a dichotomy can be appreciated between the descriptive process and the subject one; and the first one was emphasized in the developing of codes and interchange formats. Nevertheless, the studies on subject cataloguing are essential to support the creation of information products able to support subject retrieval and, in general, document-based research.
\end{abstract}

Keywords: Subject Cataloguing. Charles Ammi Cutter. Subject Cataloguing Rules. Subject headings.

No entanto, como é natural, em cada país e mesmo em regiões onde a Biblioteconomia passou a ser desenvolvida adquiriu contornos próprios e dessa forma, enquanto na Europa enfatizou as questões teóricas e conceituais da Documentação e da Biblioteconomia, na América do Norte ela se voltou às questões pragmáticas, como afirma Guimarães (2009) ao delinear as linhas teóricas de desenvolvimento a partir do percurso teórico do tratamento temático da informação.

Nesse cenário, os catálogos surgiram como simples inventários de acervos, mas se tornaram os elementos-chave no escopo da organização da informação. Conforme Ferraz (1991) "a introdução do catálogo na história da humanidade passou a caracterizar a biblioteca não como mero depósito de livros". Assim, entendese que sem o catálogo a biblioteca torna-se de fato apenas um depósito, pois é através do catálogo que: "[...] o usuário pode encontrar duas importantes peças de informação: se a biblioteca possui o item desejado e, se tem, onde ele está localizado na coleção". (Ferraz, 1991, p. 
91). Acredita-se que sem essa ferramenta fundamental, a maior parte dos usuários não dedicaria uma parcela do seu tempo a procurar algo que não sabe em que local do acervo está ou mesmo se existe naquela coleção.

O desenvolvimento dos catálogos deu origem a um dos processos mais significativos da área de organização da informação: a Catalogação. Processo mediador que permite que as obras contidas no acervo sejam conhecidas, buscadas e acessáveis.

O percurso histórico da Catalogação marca diferentes mudanças de paradigmas ocorridas na história da organização, como a própria transição de imagem e papel da biblioteca de depósito para centro de disseminação da informação. Um dos fatores que contribuiu categoricamente para a democratização do acesso à informação, e consequente pilar ao desenvolvimento da sociedade, principalmente em países desenvolvidos como os europeus e Estados Unidos, onde há uma postura de valorização das bibliotecas, o que fica evidenciado em grandes bibliotecas como a Library of Congress (LC), New York Public Library, Biblioteca do Vaticano, Biblioteca de Oxford, Biblioteca Nacional de España, entre outras.

Dentro deste contexto inicia-se a sistematização da Catalogação de Assunto (subject cataloging), que permitiu o acesso por assunto no catálogo. Charles Ammi Cutter foi pioneiro ao propor princípios norteadores para o catalogador ao construir os cabeçalhos de assunto no catálogo. A obra de Cutter durante muito tempo foi a única a tratar de aspectos para catalogação de assunto até 1920 com a publicação do código de catalogação da Biblioteca Apostólica Vaticana, que continha extenso estudo dedicado aos cabeçalhos de assunto, no qual recebeu influência da obra de Cutter.

Obviamente não podemos ignorar a contribuição européia para a catalogação. No entanto, o enfoque dado no presente artigo está direcionado ao desenvolvimento ocorrido exclusivamente no âmbito da biblioteconomia norteamericana na perspectiva da catalogação de assunto (Foskett, 1973) sendo que essa passou a ser um pólo norteador da biblioteconomia em grande parte do mundo, incluindo o Brasil.

Um breve olhar sobre a literatura internacional percebe-se que os estudos referentes à sistematização da catalogação de assunto são modestos quando comparados com a catalogação descritiva, que recebeu maior ênfase na sistematização do seu processo.
Posto isso, o objetivo do nosso trabalho foi fazer breve resgate histórico bibliográfico da catalogação de assunto, enquanto processo mediador da organização e representação da informação, tendo como foco alguns problemas decorrentes da ausência de códigos norteadores para catalogação de assunto e a própria dificuldade de implementá-los a partir da perspectiva norteamericana.

\section{O contexto da catalogação de assunto}

Inserida na área de organização e representação da informação o processo de catalogação subentende operações realizadas sobre um item com o objetivo de descrevê-lo a partir de suas características físicas, bibliográficas e conteúdo intelectual, que resultarão no estabelecimento de pontos de acesso para a identificação e recuperação do material. (Garrido Arilla, 1996).

Como "material" devemos entender uma obra/item ou recurso documental a ser representado, pertencente ao acervo. A diferença entre obra e item é esclarecida por Mey (2003) cuja obra é a criação intelectual, artística, registro do conhecimento, entidade abstrata etc., que está materializada em algum suporte físico, concreto (item ou recurso), passível de inclusão no acervo e representada no catálogo.

O catálogo numa concepção mais atual é idealizado por Mey e Silveira (2009, p. 12) como:

[...] um meio de comunicação, que veicula mensagens sobre os registros do conhecimento, de um ou vários acervos, reais ou ciberespaciais, apresentando-as com sintaxe e semântica próprias e reunindo os registros do conhecimento por semelhanças, para os usuários desses acervos. O catálogo explicita, por meio das mensagens, os atributos das entidades e os relacionamentos entre elas.

O objetivo da criação dos catálogos, não constitui atividade simplória, pois conforme as características descritas por Wynar (1976) o catálogo deve informar se (a) um determinado livro existe na biblioteca; (b) quais os trabalhos de um autor específico estão na coleção; (c) quais as edições de um trabalho específico a biblioteca tem e (d) quais materiais a biblioteca possui em um determinado assunto. Esta última prerrogativa dos catálogos tem sido justamente a mais complexa no decorrer do seu desenvolvimento.

Diante o exposto, pode-se dizer que a catalogação compreende dois processos mediatizados e inter-relacionados: a primeira etapa, chamada de catalogação descritiva, correspondente à identificação de elementos físicos do item e a segunda etapa concernente a catalogação de assunto é responsável pela extração do con- 
teúdo temático para atribuição de pontos de acesso por assunto, que constituirão os cabeçalhos de assunto. Entende-se por cabeçalho de assunto, o vocabulário controlado que padroniza e uniformiza a descrição sintética dos assuntos da obra no catálogo.

Para Tauber (1953), a catalogação descritiva contribui para a identificação de um livro específico com o propósito de distingui-lo entre outros. Já a catalogação de assunto analisa o conteúdo do documento e o representa a partir da construção dos cabeçalhos de assunto, bem como é feita a sua classificação numérica com vistas ao arranjo no acervo e a adequação à sua inclusão no catálogo da biblioteca, permitindo assim identificação por áreas temáticas.

Compete ao catalogador identificar o assunto do documento e selecionar os termos para representá-lo com precisão no catálogo (Mann, 1962).

$O$ resultado da obra catalogada quando de forma eficaz permite ao usuário buscar e recuperar documentos que o acervo possui em torno do seu assunto de interesse permitindo sua localização. Sendo a busca por assunto "a área mais problemática da pesquisa" (Feather, Sturges, 2003), mas ainda assim é a função mais importante do catálogo, se caracterizando como peça chave para recuperação do documento, pois segundo Shera e Egan (1969), Teixeira (1979), Mey (1987) e Taylor (1995) esse é o tipo de busca mais utilizado pelo usuário. Por isso, destaca-se a importância da catalogação em atribuir os pontos de acesso de assunto para construção e manutenção dos catálogos, produtos deste processo.

A catalogação enquanto forma de representação não é uma atividade recente na nossa história. Sua origem está calcada na construção de catálogos como forma de representar e organizar o conhecimento armazenado nas primeiras bibliotecas da Antiguidade. Durante muito tempo a catalogação foi definida (Wynar, 1976; Costa, 1943) como o processo de elaboração dos catálogos - seu principal produto.

Todavia Mey e Silveira (2009) destacam que esta tradicional definição caracteriza o processo como "restritivo e simplista", pois afirmam que a catalogação não apenas descreve os documentos, mas os individualiza, os torna únicos e os reúne por suas semelhanças e relacionamentos dispostos no catálogo.

Sem dúvida é indiscutível esta visão das autoras em atribuir maior significação e responsabilidade para a catalogação, haja vista sua importância. Entretanto contrapomos o aspecto "simplista" designado à construção dos catálo- gos, por acreditar que não se trata de uma atividade insubstancial, já que o catálogo deve permitir ao usuário: localizar, identificar, selecionar, adquirir e navegar, deve ter flexibilidade, facilidade de manuseio, portabilidade, compacidade, uniformidade e atualidade (Mey; Silveira, 2009). Ou seja, sua elaboração envolve diferentes aspectos que devem ser considerados, por isso, percebe-se quão complexo é o preparo de um catálogo, que envolve ainda constantes reavaliações e readaptações, tanto em catálogos manuais como principalmente nos atuais catálogos automatizados tais como os OPAC (Online Public Access Catalog).

A partir disso permite que a obra seja buscada e recuperada pelo usuário, objetivo principal da representação. Sendo processo essencial (Costa, 1943) para o pleno funcionamento dos fluxos informacionais nos sistemas de informação.

A catalogação ao longo de sua história se utilizou de diferentes "tecnologias" disponíveis em cada época para propiciar a organização do conhecimento, desde tabletes de argila até os atuais recursos digitais. Os trabalhos de Gates (1968), Dias (1967) Bakewell (1974), Fiuza (1987), Ferraz (1991), Garrido Arrilla (1996) e Mey e Silveira (2009) fazem resgate histórico dos catálogos desde a Antiguidade e destacam diferentes fatos importantes que contribuíram significativamente para a catalogação. $O$ mais antigo registro deles foi encontrado próximo a Fenícia, datado de três mil anos antes de Cristo, contendo aproximadamente dezessete mil tábuas de argilas em escrita cuneiforme relativos a quatro mil documentos, organizados e representados na estante pelo conteúdo temático, alguns deles contendo inclusive o resumo da obra. (Mey; Silveira, 2009).

$\mathrm{Na}$ Europa, durante a Idade Média há relatos de catálogos construídos em bibliotecas monásticas na França, Itália, Alemanha e Inglaterra, que embora não obedecessem a critérios normativos para sua construção, contribuíram significativamente para avanço e desenvolvimento dos catálogos.

Outros registros apontam que ainda na Europa do século XIII alguns mosteiros ingleses realizaram uma tentativa de criação de um catálogo coletivo de seus acervos. Já no século XIV surge a idéia da utilização de símbolos para localização dos livros nas estantes. Foi na Europa que ocorreram às primeiras iniciativas de sistematização dos catálogos com Hernando Colón na Espanha, Frei beneditino Florian Trefler na Alemanha e Andrew Maunsell em Londres.

Nota-se que o catálogo enquanto produto da representação da informação desempenhou 
papel decisivo para o estudo e aprimoramento da catalogação. O que incidiu alguns pesquisadores contemporâneos a se dedicaram ao estudo do catálogo, visando sua construção a partir das funções que ele deveria desempenhar. Tendo em vista inclusive o crescimento exponencial da produção bibliográfica.

Para Cutter (1891) a função do catálogo era: (a) permitir que o livro fosse encontrado a partir do conhecimento de seu autor, título ou assunto; (b) apresentar o que existe no acervo da biblioteca sobre determinado autor e assunto e (c) auxiliar na seleção de um livro para consulta.

Lubetzky (1960) também acreditava na necessidade do catálogo "servir ao usuário". Segundo sua concepção o catálogo deveria ser simples, lógico e coerente e apresentar ao usuário as obras que a biblioteca possui, bem como as obras relacionadas que contemplassem o propósito do usuário.

Assim como Cutter e Lubetzky, os objetivos do catálogo para Ranganathan (1967) deveriam ser direcionados para pessoa acervo, com base nas cinco leis da Biblioteconomia nos quais o catálogo deveria ser desenvolvido para revelar a cada documento o seu leitor e vice-versa, poupando o tempo do leitor e o tempo da equipe de trabalho.

Para Lancaster (1977) "o catálogo é a mais importante chave para a coleção da biblioteca" e sua função maior é saber se a biblioteca possui um item bibliográfico específico cujo autor e/ou título são conhecidos [...] e se assim for, onde está localizado".

Outra referência importante é a obra de Guinchat e Menou (1981), para os quais a idéia principal de um catálogo é que ele permita aos usuários conhecer quais são as obras e os itens pertencentes ao acervo antes mesmo que se tenha acesso aos documentos em si.

No tocante a isso Frarey (1953) afirma que na literatura há certa falta de consenso entre as funções/ objetivos do catálogo, o que particularmente prejudica a própria função da catalogação de assunto e da indexação. Para ele a própria definição de Cutter é contraditória, pois menciona o estabelecimento de referências cruzadas a partir do princípio sindético, através da qual, relacionam-se os assuntos correlatos.

Frarey (1953) observa que até a década de 1950 embora os catalogadores tivessem preocupação com o usuário, não tinham estudos que norteassem esta abordagem, apenas existia suposições daquilo que acreditavam ser, só a partir dessa década foram iniciadas as investigações. Essa necessidade de compreender a perspectiva do usuário não se insere apenas no momento de construção dos catálogos e cabeçalhos de assuntos, mas envolve aspectos inerentes a própria avaliação e adaptação do sistema, bem como a construção dos instrumentos utilizados tais como as linguagens documentais adotadas para representação da informação. Tendo em vista que se os objetivos do catálogo não estão sendo alcançados é porque existem falhas em determinados pontos que precisam ser revistos, avaliados e adaptados.

Ademais vale destacar dois fatos marcantes para a história da catalogação que foram a mudança no formato de construção dos catálogos de rígidos livros para fichas, e também de manuais para catálogos eletrônicos e em linhas. Estas mudanças resultaram em aspectos positivos não apenas econômicos, mas também processuais, diminuindo os custos e o tempo de trabalho. Neste cenário a Library of Congress exerceu importante papel ao oferecer o serviço de fichas impressas prontas, permitindo a padronização na forma de catalogar. Isto caracterizou a prática norte-americana da moderna catalogação, visto que os códigos passaram a ser projetados para o catálogo em fichas.

Outros marcos foram decisivos para catalogação com o objetivo de alicerçá-la enquanto campo teórico e pragmático da organização da informação. No século XIX na Europa Anthony Panizzi ao propor as 91 regras de catalogação (considerado o primeiro código oficial de catalogação), influenciou todos os demais códigos subsequentes. Já nos Estados Unidos a publicação dos códigos Jewett e de Cutter, e também as contribuições das Instruções Prussianas (Alemanha), da American Library Association (ALA), Código da Vaticana (Itália), Seymour Lubetzky e a International Conference on Cataloging Principles na década de 1960.

Recentemente foram publicados novos requisitos para catalogação como a proposta da International Federation of Library Associations and Institutions (IFLA) nomeado FRBR (Functional Requirements for Bibliographic Records) para explicar a busca, identificaç ão, seleção e obtenção de funções de catálogos (Feather, Sturges, 2003).

Percebe-se que todos os esforços nas definições de códigos e princípios de catalogação que a faceta da catalogação de assunto, encontrou sérias dificuldades em alcançar ao menos propostas mais viáveis para a criação de regras ou códigos internacionais.

Neste contexto nota-se que os objetivos e desenvolvimento dos catálogos acompanharam a partir de uma "simbiose" a mudança de para- 
digma do papel da biblioteca, de armazém de livros para provedor da informação, a partir da demanda social que foi imposta. Isto contribui em muito para aperfeiçoamentos dos catálogos, até os dias atuais, tais como os catálogos em linha, que exigiu dos bibliotecários rediscutirem as funções do catálogo, principalmente do catálogo de assunto.

O catálogo se destaca como produto essencial para organização, representação e acesso a informação. No entanto não deve existir como um fim em si mesmo, pois ele se insere em um sistema informacional e deve estar sensível a mudanças cotidianas a partir da necessidade informacional registradas pelos usuários.

A isso se insere o surgimento e necessidade dos catálogos de assunto, sistematizados a partir da catalogação de assunto, que historicamente podem ser caracterizados em duas vertentes: o catálogo dicionário e o catálogo sistemático (Guinchat, Menou, 1981), este último atualmente em desuso tem por suporte o catálogo alfabético de assunto (que não tem preocupação com o controle de sinonímia) para localização do número de classificação.

Observa-se que com o advento dos recursos eletrônicos os catálogos sofreram forte impacto no seu modo de construção, apresentando novas perspectivas. Todavia Fiuza (1987) relembra que em 1977 Lubetzky alertava que o uso de novas tecnologias só corroborava as funções básicas do catálogo e da importância em ter em mente os objetivos do catálogo ao utilizar novos recursos digitais.

Assim, mesmo com as facilidades e "seduções" da tecnologia atual, o catálogo deve ser construído com respaldo científico, cujas regras, normas e regulamentos possam garantir uniformidade, padronização, exatidão, lógica e credibilidade (Mann, 1962), permitindo o fácil entendimento e manuseio pelo usuário no momento que elabora suas estratégias de busca.

No tocante a isso se destaca as Rules for a catalog dictionary, obra fundamental de Cutter.

\section{Discutindo as regras para a catalogação de assunto}

Os estudos e a atuação biblioteconômica de Charles Cutter (1837-1906) contribuíram para o desenvolvimento moderno dos catálogos. Joudrey (2005) afirma que as idéias de Cutter e seus objetivos têm por mais de um século inspirado profissionais e os feito lembrar-se de sua obrigação em fornecer aos usuários diferentes formas de acessar a informação, o que inclui o acesso também pelos assuntos das obras.
Cutter não foi o primeiro a abordar questões relativas à Catalogação, mas segundo ele, haviam vários conjuntos de regras de catalogação, no entanto, não havia nenhum manual para o catálogo-dicionário. Os trabalhos anteriores não haviam tentado sistematizar os princípios da catalogação de assunto numa abordagem mais pragmática.

Cutter ao lançar as "Rules for a dictionary catalog" em 1876 foi o precursor de tais regras para catalogação de assunto e definição dos cabeçalhos. A obra que evoluiu em quatro edições se constitui em um código com 369 regras relativas à catalogação descritiva e catalogação de assunto. Na concepção de Foskett (1973) as contribuições de Cutter "formaram a base da prática norte-americana em matéria de catalogação de assuntos" e também marcaram profundamente a Biblioteconomia internacional. Cutter a partir dos cargos que ocupou na ALA pode auxiliar nas idealizações das regras angloamericanas ao longo do século $X X$, chegando até a publicação do AACR-1 (Garrido Arilla, 1996).

Segundo Reynolds (1989) embora as regras de Cutter para o catálogo dicionário não tenham sido formalmente adotadas pela Library of Congress elas fazem parte da base filosófica da LC para catalogação de assunto. Ela ainda destaca que a ausência formal de um código de catalogação de assunto que norteasse os catalogadores, contribuiu para a consolidação da LC como autoridade quando iniciou o comércio de venda de fichas catalográficas e determinação dos cabeçalhos de assunto a partir da compilação da Library of Congress Subject Headings (LCSH) atualmente na sua $31^{\text {a }}$ edição, ditando padrões definidos para os cabeçalhos de assuntos.

A LCSH foi o padrão adotado na maioria das bibliotecas americanas e consequentemente em países que receberam influência direta da $L C$, tal como o Brasil, no qual muitas bibliotecas atualmente utilizam o sistema Bibliodata (baseado na LCSH) coordenado pela Biblioteca Nacional e a Fundação Getúlio Vargas. Bem como a utilização da Sears list of subject headings (forma condensada da LCSH) que foi traduzido para o português por Wanda Ferraz (1977) na década de 1940 sob título "Relação de assuntos para cabeçalhos de fichas", obra que foi muito utilizada pelas bibliotecas publicas brasileiras.

O padrão de instrumento da catalogação de assunto para bibliotecas norte-americanas (Young,1990) são as linguagens précoordenadas: LCSH, Library of Congress Classification (LCC) e Dewey Decimal Classification (CDD) e se caracterizam como importantes 
instrumentos para realização da catalogação de assunto. No entanto, Young observa que eles sofreram grandes prejuízos no decorrer do último século não sendo bem integrados aos atuais sistemas de informação existentes, tais como os catálogos em linha que propiciam diferentes estratégias de buscas tais como as possibilidades apresentadas pelos operadores booleanos e utilização de linguagens pós-coordenadas.

Reynolds (1989) menciona que a LCSH apresenta diversidade de cabeçalhos de assuntos que refletem filosofias que estavam em voga na época que foram estabelecidos, por isso estas inconsistências internas da LCSH se baseiam em precedentes e analogias ao invés de regras formais. Para a autora, pode ser possível sistematizar cabeçalhos de assunto como a LC vem tentando fazer, no entanto é muito mais difícil discernir uma concepção coerente subjacente a um sistema que é baseado em prática de mais de um século de diferentes filosofias.

Ao contemplar o histórico da catalogação, percebe-se claramente que o desenvolvimento das regras e normas para catalogação descritiva a partir da elaboração dos códigos AACR (Angloamericano cataloging rules) e das ISBD (International standard bibliographic description), foram mais incisivos se comparados com a catalogação de assunto. O que suscita questionamentos sobre os motivos que inibiram sua sistematização.

A este respeito Reynolds (1989) supõe que a continua revisão do AACR coibiu o desenvolvimento do código de catalogação de assunto, por acreditar que os bibliotecários imaginarem que até aquela época, (a) os usuários da biblioteca tinham conhecimento sobre o documento a ser utilizado (a isso se supõe acesso a biblioteca por grupos minoritários e pouca produção?); (b) que as entradas de título e autor permitiam o usuário localizar o documento (Costa, 1943) e (c) pela abstração dos cabeçalhos de assunto e a dificuldade de codificá-los.

Os argumentos (a) e (b) - a nosso ver, não justificam a falta de sistematização dos códigos de catalogação de assunto, tendo em vista que os catálogos de assunto surgiram frente à demanda em se buscar informação a partir das necessidades de conhecimento. $O$ que também resgata que nesta época já havia ocorrido a conhecida "explosão informacional" (o que talvez justificasse a excessiva demanda de materiais versus pouco recurso técnico e humano que suprisse o trabalho) bem como o acesso de classes populares ao uso das bibliotecas. Já o argumento (c) ainda hoje encontra dificuldade de metodização, o que culmina a necessidade de aprofundar estudos nesta área.

Em 1941 a ALA publicou um documento no qual definia um conjunto de regras para catalogação, esta obra foi "o produto de um trabalho devotado de muitas pessoas hábeis" (Dunkin, 1977). Nesse mesmo ano, esse documento sofreu a crítica de Andrew D. Osborn que publicou o artigo "The Crisis in Cataloging", no qual denunciava uma catalogação "legalística" (legalistic cataloging).

Para Osborn (1941), assim como Cutter a catalogação é uma arte (Dunkin,1977), como toda arte, deve possuir um conjunto básico de técnicas e regras simples a serem seguidas. Osborn admitiu que esse era um ponto de vista romântico, mas que a catalogação estava ficando excessivamente regrada. Para ele haviam três defeitos principais na abordagem legalista da catalogação: (1) as regras tentam abranger questões de gosto e juízo que devem ser deixadas indefinidas; (2) o alto custo do debate e definição das regras continuará pra sempre (3) a codificação tende a obscurecer razões e princípios. Elementos da prática de catalogação que foram introduzidas por razões históricas, passaram a ser perpetuados sem nenhuma compreensão do motivo pelo qual a regra foi feita. Osborn, também via uma forma de economizar dinheiro, para Dunkin (1977): "atrás do profeta que queria simplificação para salvar princípios básicos, estava o administrador de bibliotecas que queria simplificação apenas para economizar dinheiro."

Se por um lado a classe bibliotecária (não apenas norte-americana, mas em âmbito internacional) se envolveu diretamente para o desenvolvimento de padrões que conferissem uniformidade e intercâmbio para catalogação descritiva, por outro lado a precariedade de eventos científicos e profissionais, bem como a carência de estudo para catalogação de assunto foi determinante para ausência de códigos de catalogação (Young, 1990).

Isso insere a própria percepção da catalogação como "arte", que teve impacto mais incisivo na catalogação de assunto e demais processos de representação temática. A própria literatura tratava a execução destas atividades como arte e fruto de talento especial apenas com parâmetros subjetivos do uso do bom senso, como destaca os estudos de Mey (1887), Campos (1987), Cunha (1989) e Guimarães (2003).

Talvez se possa afirmar que a própria questão do uso do bom senso pelos catalogadores pode ter interferido na ausência de metodização na catalogação de assunto, até mesmo por acredi- 
tarem que o processo de determinação do assunto é subjetivo.

A este respeito Guimarães (2007) esclarece que nas últimas décadas a área de tratamento temático "vem percorrendo uma trajetória que reúne a dimensão pragmática dos instrumentos à busca por uma base epistemológica que a explique e sustente", com o propósito de conferir cientificidade nos seus métodos.

Ademais, Young (1990) e Reynolds (1989) de modo semelhante acreditam que a contribuição da obra de Cutter (que tinha por base todos os elementos de catalogação num único código) foi imediatamente dividida e desenvolvida separadamente. Primeiro a separação da catalogação de assunto e classificação na LC, depois pela catalogação de assunto e catalogação descritiva (incluindo escolha e forma de nomes próprios). Isso resultou em diferentes expansões pela Library of Congress e demais órgãos institucionais como ALA, que deixou em segundo plano a catalogação de assunto, não dando aperfeiçoamento ou estudo mais aprofundado aos cabeçalhos de assunto.

Tendo em vista a insuficiência de alguns aspectos em suprir determinadas questões da representação de assunto, conduziu muitos teóricos da área de catalogação a tratar os cabeçalhos de assunto de modo resumido, orientando a utilização de listas impressas. Já que durante muito tempo, as escolas de Biblioteconomia contavam apenas com as regras de Cutter para embasamento teórico (Dias, 1967).

Chan (1989) discute a questão da implementação de um código indagando algumas questões: o que é um Código de catalogação de assunto? Nós precisamos de um Código de catalogação de assunto? É economicamente viável desenvolver tal código neste momento? Quem vai desenvolver? Seria o código a solução para padronizar o estabelecimento de assunto?.

O próprio autor buscou resposta para seus questionamentos a respeitos dos códigos:

1. Tomando como base a definição de que um Código é um "conjunto de regras ou princípios", tomaremos como protótipo o AACR2, que tem duas funções: fornecer um conjunto de princípios com a fundamentação teórica e conceitual e dar instruções na implementação desses princípios na forma de regras específicas. Assim, ocorre uma questão relacionada: que tipo de Código se almeja? Um código totalmente baseado nos fundamentos lógicos e teóricos, ou um código baseado na prática corrente? A primeira alternativa é ten- tadora, no entanto, apresentaria problemas sérios na sua implementação. A segunda alternativa parece mais amena, mas também apresentaria dificuldades em termos de resolver problemas ocorrentes na prática atual.

2. Vários autores já afirmaram a necessidade de um Código, mas não é propósito discutir isso nesse momento. No entanto, o Código deveria fornecer somente as regras para estabelecer os cabeçalhos de assunto apenas? Ou deveria também cobrir as aplicações desses cabeçalhos e orientações sobre a construção das linguagens documentais utilizadas para determinação dos cabeçalhos de assunto?.

3. Essa é certamente a questão principal e sua resposta será provavelmente determinante. A complexidade de um cabeçalho de assunto e sua aplicação farão o desenvolvimento do AACR2 parecer uma "brincadeira infantil". Muito dinheiro e energia deverão ser empregados nisso, e a primeira coisa é estarmos certos de que teremos os recursos suficientes para tal empreendimento.

4. Para esta última questão o autor apresenta duas alternativas: (1) construção do Código fora da Library of Congress (2) pela Library of Congress e propõe três possiveis critérios para essa escolha: (1) recursos disponíveis (2) eficácia e eficiência (3) implicações para implementação.

Ainda em relação à criação do código de catalogação de assunto, é interessante que Cutter (1891) iniciou o texto de Rules for a dictionary catalog com a seguinte afirmação:

Nenhum código de catalogação pode ser adotado em todos seus pontos por todo mundo, pois as bibliotecas para estudantes e as bibliotecas para leitura tem objetivos diferentes, e algumas combinam as duas em diferentes proporções.

Haja vista a própria dificuldade da representação da informação tendo por foco as necessidades dos usuários, devendo considerar aspectos como o pluralismo cultural, interdisciplinaridade dos diferentes domínios do conhecimento, aspectos éticos e semânticos.

Todavia, as tentativas mais próximas de códigos numa perspectiva norte-americana para catalogação de assunto foram estabelecidas por Haykin em sua obra Subject Headings: A Practical Guide publicada em 1951 e o manual da Library of Congress's Subject Cataloging Manual: Subject Headings ambos tentaram especificar os procedimentos e políticas utilizados pela LC, no entanto, não eram códigos. 
Reynolds (1989) afirma que um possível código de catalogação de assunto deve prover ao catalogador orientações sobre a determinação dos assuntos num documento e permitir que outros avaliem a decisão do catalogador, consentindo que documentos semelhantes possam receber tratamento consistente, mesmo se forem catalogados por outros profissionais. O código também deveria especificar a forma de traduzir assuntos/conceitos contidos no documento em cabeçalhos de assunto.

Essa é outra dificuldade a ser destacada por Young (1990) e implica necessidade de estudos aprofundados no âmbito da construção das linguagens documentais e principalmente da análise de assunto, pois ainda hoje há questionamentos sobre o próprio conceito do que seja assunto e a ausência de especificações do processo de análise para se determinar o que trata o documento (Hutchins,1977).

Problema que não ocorre na catalogação descritiva, pois além de claros e definidos os pontos que serão representados - mesmo em suportes digitais, o catalogador tem auxílio dos instrumentos que foram construídos e adaptados no último século e estão em constantes aperfeiçoamentos. No entanto, ao se referir à catalogação de assunto e as questões inerentes a ela, a dificuldade permanece em evidência: como saber em um documento qual é o seu assunto?.

Estudiosos como Cutter e Ranganathan entenderam esta problemática e tentaram delimitar 0 que seria assunto. Para Hutchins este é o ponto nuclear da Ciência da Informação e denomina como aboutness este conceito. Esta dificuldade vai ao encontro da visão de Reynolds (1989) quando afirma que a confusão sobre os objetivos do catálogo talvez derive da indefinição em delimitar o que é assunto. Para autora o grande enigma da catalogação de assunto consiste em determinar qual o aboutness do documento e traduzi-lo em cabeçalhos de assunto.

Para Young (1990) estes problemas resultantes da catalogação de assunto evidenciam que falta base conceitual para suportar a diversidade atual de suportes que integram os sistemas informacionais. Ainda mais com a crescente utilização dos catálogos em linha, que diferente dos manuais, permitem a utilização de diferentes estratégias de busca, o uso da websemântica e participação ativa/direta dos usuários na construção da representação e os novos tipos de acesso a diferentes multimídias. Embora os OPAC's e demais sistemas de representação e acesso eletrônicos à informação tenham quebrado barreiras e ampliado o potencial dos acervos, no entanto ainda hoje permanecem os desafios de construção dessas ferramentas ainda similares aos catálogos manuais, tendo em vista que as questões de ordem social, lingüística e ética, entre outros, permanecem, e na verdade são até mesmo ampliadas, pois sendo seu alcance muito mais abrangente que $o$ de uma comunidade local, mais critérios devem ser englobados.

Progressos substanciais ocorreram nos últimos anos a partir da convergência entre a Biblioteconomia e a Ciência da informação, que tem buscado a contribuição de outros campos científicos.

Em âmbito brasileiro os estudos coordenados por Fujita (2003a; 2003b) com abordagem Sociocognitiva buscam a compreensão dos processos mentais que o profissional catalogador de assunto desenvolve durante a identificação do assunto em um documento. Esta perspectiva sociocognitiva tem se destacado de modo significativo para prática de catalogação de assunto porque seu objetivo centra-se na recuperação da informação e envolve, além do catalogador, seu contexto sociocognitivo de produção composto por usuários, métodos, técnicas, materiais e ambiente desse processo. Portanto, pode ter como foco o sujeito que realiza determinada atividade e sua cognição em relação ao seu contexto de produção no contexto de tratamento da informação pelo catalogador de assunto.

A idealização de um código de catalogação de assunto esbarra nesta questão de descrição do conteúdo. Para Cesarino e Pinto (1978) este é o maior problema da catalogação de assunto, "talvez por ser menos reduzível a regras e por trabalharmos com fatores que não identificam realmente uma determinada obra".

Outra questão envolvida é com relação às listas de cabeçalhos de assunto, tesauros, índices e até mesmo as próprias ontologias cujos aspectos como: garantia literária e cultural, hospitalidade cultural, vocabulário, sintaxe, terminologia, semântica (Beghtol, 2005; Cesarino; Pinto, 1978) devem refletir a realidade dos usuários ao ser adotadas pelas unidades de informação, o que dificulta possível padronização. $O$ que resgata a necessidade de investigação teórica sobre os próprios instrumentos utilizados para a representação da informação.

Cesarino e Pinto (1078) esclarecem que não pode haver rigidez quanto ao emprego da representação dos cabeçalhos de assunto no catálogo. A comunidade a qual o catálogo serve deve se identificar, permitindo que ele vá ao encontro de suas demandas informacionais. A isso se agrega as próprias políticas de inde- 
xação e catalogação de assunto da unidade, que vão se comportar de modos diferentes. Principalmente nesta atual era digital sem fronteiras, que permitiu a globalização dos catálogos. O que suscita novos e velhos paradigmas para área de catalogação de assunto que devem ser discutidos.

\section{Considerações}

A catalogação de assunto apresenta entraves de ordem prática bastante pungentes, como evidenciamos na revisão de literatura apresentada.

No entanto, desde que o atual direcionamento dos sistemas de informação tem passado a se pautar muito mais no conteúdo das obras do que em sua forma física, é necessária a busca por uma melhor crítica e sistematização das formas pelas quais os documentos são tematicamente representados.

Embora vejamos nessa questão um problema angustiante frente à produção de materiais e a capacidade das organizações de processá-la e disseminá-la, compreendemos que talvez estejamos em um momento histórico onde de fato as atenções se voltem cada vez mais para essa necessidade. Considerando que o controle bibliográfico conseguiu enormes avanços com o desenvolvimento dos padrões descritivos que propiciaram redes bibliográficas mundiais (embora ainda haja muito a ser solucionado), é muito provável que o momento histórico que se configura se direcione de fato para essa demanda da representação temática.

Observando a velocidade com que as ferramentas tecnológicas têm sido desenvolvidas, é necessário então que as bibliotecas e instituições que utilizem os cabeçalhos de assunto possam também acompanhar tais mudanças e prover produtos cada vez mais eficientes.

Outro ponto a ser considerado no possível desenvolvimento de códigos ou regras é o trabalho conjunto entre as esferas acadêmica, profissional e comunidade, no intuito de confluir esforços para sua sistematização. Com base na construção de um modelo operativo que descreva e delimite todas as fases do processo de catalogação de assunto que possa orientar os profissionais durante sua execução. O que possibilita sua análise para possíveis avaliações, adaptações e evolução. Tendo em vista que este processo recebe influencias diretas do contexto sociocognitivo do profissional, da instituição, das políticas de indexação, do usuário/leitor que incidem de modo ativo e direto na catalogação de assunto. O modelo teria como propósito mi- nimizar a subjetividade inerente ao processo e proporcionar melhor detalhamento da sistematização para a implementação de um possível código.

Esse trabalho buscou trazer alguns subsídios a discussão teórica em torno dos catálogos de assunto. Pode-se afirmar que a eficácia do catálogo de assunto pode ser quantificada e qualificada a partir da sua capacidade de conduzir os usuários às informações de que necessitam.

A eficácia geralmente respalda-se na medida em que todos os materiais relevantes no sistema são identificados na busca (revocação), porém nenhum material irrelevante é identificado (precisão).

Por isso, se não houver princípios norteadores que orientem o catalogador de assunto no momento de representar o documento, há o risco de basear-se somente em critérios subjetivos ou no seu próprio "bom senso" em detrimento a cientificidade do trabalho, que justifique os meios e os caminhos percorridos por ele na representação, pois compete ao catalogador identificar a relevância e especificidade ao determinar quais serão os cabeçalhos de assunto que representarão o documento. Nisso se insere o modo como tais instrumentos de representação (sistemas de classificação, tesauros, ontologias, listas de cabeçalhos de assuntos) tem sido construídos, sobre quais parâmetros são sistematizados, avaliados e selecionados para representar a informação?

A premissa dessa discussão é que um provável código de catalogação de assunto deve ser baseado em estudos teóricos (sem ignorar a prática) e não consiste apenas em racionalizar procedimentos de modo arbitrário, mas sim criar condições para que possam também ser avaliados os princípios que forem propostos.

\section{Referências}

Bakewell, K. G. B. (1972). A manual of cataloguing practice. Oxford, Eng.: Pergamon, 1972.

Beghtol, C. (2005) Ethical decision-making for knowledge representation and organization systems for global use. // Journal of Documentation. 56:9 (2005) 903-912.

Cesarino, M. A. da N.; Pinto, M. C. M. F. (1978). Cabeçalho de assunto como linguagem de indexação. // Revista escola de biblioteconomia da UFMG. 7:2 (1978) 268-88.

Chan, L. M. (1989). A subject cataloging code? // Cataloging and classification quarterly. 10:2 (1989) 202-204.

Costa, J. (1943). Biblioteconomia. Porto: Tavares Martins, 1943.

Cutter, C. A. (1891) Rules for a dictionary catalog. 3. ed. rewritten. Washington, Govt. printing office, 1891.

Dias, A.C. (1967). Elementos de catalogação. Rio de Janeiro : Associação Brasileira de Bibliotecários, 1967.

Dunkin, p. S. (1969). Cataloging U.S.A. Chicago: ALA, 1969. 
Ferraz, I. M. C. (1991). Uso do catálogo de biblioteca: uma abordagem histórica. // Trans-in-formação. 3:3 (jan-dez. 1991) $90-114$

Ferraz, W. (1977). Relação de assuntos para cabeçalhos de fichas. 5.ed. Rio de Janeiro: Freitas Bastos, 1977.

Lubetzky, Seymour. (1960). Cataloging rules and principles: a critique of the ALA rules for entry and a proposed design for their revision. Washington: LC, 1960.

Foskett, A. C. (1973). A abordagem temática da informação. Tradução de Antonio Agenor Briquet de Lemos. São Paulo: Polígono, 1973.

Frarey, C. J. (1953) Developments in Subject Cataloging. // Library Trends. 2 (1953) 217-235.

Fujita, M. S. L. (2003a). A identificação de conceitos no processo de análise de assunto para indexação. // Revista Digital de Biblioteconomia e Ciência da Informação. 1:1 (2003a). http://bibli.fae.unicamp.br/revbib/index. html (20-062007).

Fujita, M. S. L. (2003b). A leitura documentária do indexador: aspectos cognitivos e lingüísticos influentes na formação do leitor profissional. 2003b. Faculdade de Filosofia e Ciências, Universidade Estadual Paulista, Marília, 2003. Tese (Livre-Docência)

Garrido Arilla, M. R. (1996). Teoria e historia de la catalocagión de documentos. Madrid: Síntesis. 1996.

Gates, J. K. (1968). Introduction to librarianship. New York: McGraw-Hill, 1968.

Guimarães, J. A. C. (2003). A análise documentária no âmbito do tratamento da informação:elementos históricos e conceituais. // Rodrigues.Georgete Medleg; Lopes. Ilza Leite. Organização e representação do conhecimento na perspectiva da Ciência da Informação. Brasilia: Thesaurus, 2003. 100-117.

Guimarães, J. A. C. (2007) A dimensão teórica do tratamento temático da informação no universo científico da International Society for Knowledge Organization - ISKO. Marília, 2007. Projeto integrado de pesquisa apresentado ao CNPq.

Guimarães, J. A. C. (2009). Abordagens teóricas de tratamento temático da informação: catalogação de assunto, indexação e análise documental. // Scire. (2009) 105117

Guinchat, C.; Menou, M. (1994). Introdução geral às ciências e técnicas da informação e documentação. Brasília: IBICT, 1994.

Haykin, D. J. (1951). Subject heading: a practical guide. Washington: Library of Congress, 1951.

Hutchins, J. W. (1977). On the problem of 'aboutness' in document analysis. // Journal of Informatics. 1:1 (1977) 17-35. http://www.scils.rutgers.edu/ muresan/551_IR/ Resources/Docs/jinfHutchins1977.pdf ( 20-01-2007).

Joudrey, D. N. (2005). Building puzzles and growing pearls: a qualitative exploration of determining aboutness. School of Information Sciences, University of Pittsburgh. 2005. Thesis.

Lancaster, F.W. (1977). The measurement and evaluations of library services. Arlington: Information Resources Press, 1977.

Mann, M. (1962). Catalogação e classificação de livros. Tradução de Washington José de Almeida Moura. Revisão de Alice Principe Barbosa. Rio de Janeiro: Fundo de cultura, 1962.

Mey, E. S. A. (1995). Introdução à catalogação. Brasília: Briquet de Lemos, 1995

Mey, E. S. A. (2003). Não brigue com a catalogação! Brasília: Briquet de Lemos, 2003.
Mey, E. S. A. (1987). Catalogação e descrição bibliográfica: contribuições a uma teoria. Brasília: Associação dos Bibliotecários do Distrito Federal, 1987.

Mey, E. S. A.; Silveira, M. C. (2009). Catalogação no plural. Brasília: Briquet de Lemos, 2009.

Osborn, A.D (1941). The crisis in cataloging. // The Library Quarterly. 11:4 (1941) 393-411.

Ranganathan, S. R. (1967). Prolegomana to library classification. Bombain, Asia Publishing House, 1967.

Reynolds, S. J. (1989). Theory There is No Solution: the Impediments to a Subject Cataloging Code. // Library Quarterly. 59:3 (july 1989) 223-238.

Shera, J. H.; Egan, M. E. (1969). Catálogo sistemático: princípios básicos e utilização. Brasília: Universidade de Brasília. 1969

Suaiden, E. J. (2000). A biblioteca pública no contexo da sociedade da informação. // Revista Ciência da Informação. 29:2 (2000) 52-60.

Tauber, M. F. (1953). Technical services in librarie: acquisitions, cataloging, classification, binding, photographic reproduction, and circulation operations. New York: Columbia University, 1953.

Taylor, A. G. (1995). On the subject of subjects. // The Journal of Academic Librarianship. 21:6 (nov.1995) 484-491.

Teixeira, J. C. (1979). Cabeçalhos de assunto: manual para estudante. Niterói: UFF, 1979.

Wynar, B. S. (1976). Introduction to cataloging and classification. Littleton, Colo.: Libraries Unlimited, 1976.

Young, J. B. (1990). Crisis in cataloging revisited: the year's work in subject analysis, 1990. // Library Resources \& Technical Services. 35:3 (1990).

Recibido: 2010-04-15. Revisado: 2010-06-29. Aceptado: 2010-07-06. 